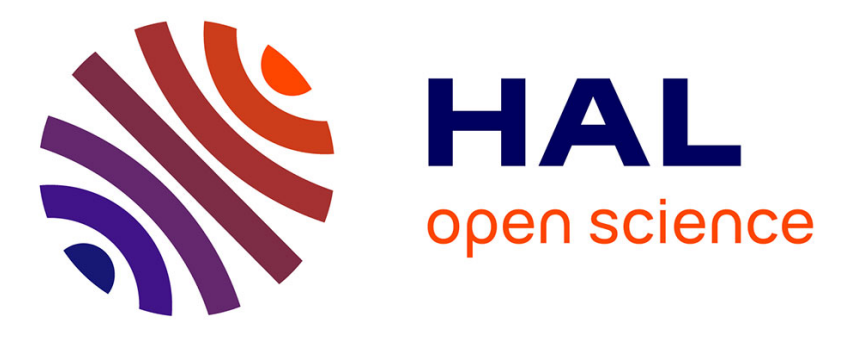

\title{
Remote Sensing Monitoring of Drought Based on Landsat8 and NDVI-Ts Characteristic Space Method
}

Shouzhen Liang, Tao Liu, Zhen Chen, Xueyan Sui, Xuehui Hou, Meng Wang, Huimin Yao

\section{- To cite this version:}

Shouzhen Liang, Tao Liu, Zhen Chen, Xueyan Sui, Xuehui Hou, et al.. Remote Sensing Monitoring of Drought Based on Landsat8 and NDVI-Ts Characteristic Space Method. 11th International Conference on Computer and Computing Technologies in Agriculture (CCTA), Aug 2017, Jilin, China. pp.116-125, 10.1007/978-3-030-06137-1_12 . hal-02124259

\section{HAL Id: hal-02124259 \\ https://hal.inria.fr/hal-02124259}

Submitted on 9 May 2019

HAL is a multi-disciplinary open access archive for the deposit and dissemination of scientific research documents, whether they are published or not. The documents may come from teaching and research institutions in France or abroad, or from public or private research centers.
L'archive ouverte pluridisciplinaire HAL, est destinée au dépôt et à la diffusion de documents scientifiques de niveau recherche, publiés ou non, émanant des établissements d'enseignement et de recherche français ou étrangers, des laboratoires publics ou privés.

\section{(ㄷ)(i)}

Distributed under a Creative Commons Attribution| 4.0 International License 


\title{
Remote Sensing Monitoring of Drought Based on Landsat8 and NDVI-Ts Characteristic Space Method
}

\author{
Shouzhen Liang ${ }^{1,2}$, Tao Liu $\left.{ }^{1,2(}\right)$, Zhen Chen $^{3}$, Xueyan Sui ${ }^{1,2}$, Xuehui Hou ${ }^{1,2}$, \\ Meng Wang ${ }^{1,2}$, and Huimin Yao ${ }^{1,2}$ \\ ${ }^{1}$ Shandong Institute of Agricultural Sustainable Development, Jinan, China \\ ${ }^{2}$ Key Laboratory of East China Urban Agriculture, Ministry of Agriculture, Jinan, China \\ \{Szliang_cas, Saaslt, sdnkysxy, sxhxh, wangm389, yhm79424\}@163.com \\ ${ }^{3}$ Weifang Bureau of Land Resources, Weifang, China \\ Chenzhen0608@126.com
}

\begin{abstract}
Drought has an important impact to agriculture, and its monitoring is very necessary for many regions subjected to drought in Shandong province. Gaomi city of Shandong was chosen as a study area to probe remote sensing monitoring method of drought. Landsat8 satellite data and soil volumetric moisture content data from filed investigation were used. Temperaturevegetation method was adopted to monitor drought in the study area. The results showed that land surface temperature was negatively related to NDVI. Temperature vegetation dryness index(TVDI) had a significant correlation with soil water content. TVDI can reflect the drought in the study. It suggests that TVDI can be used as a effective index to monitor drought in the study area.
\end{abstract}

Keywords: Remote sensing· Drought· NDVI· Temperature

\section{Introduction}

Drought is a frequently-occurred natural hazard and it can last for months, even years. It has a substantial impact on the ecosystem and agriculture and harm to the local economy. Water resources are limited, so how to rapidly respond to drought and carry out farmland irrigation efficiently in order to guarantee the reasonable and effective utilization of water resources, and ensure normal food production is a very important question. To resolve the question, it becomes very necessary to timely and accurately identifies the area, degree of the drought.

Drought monitoring based on remote sensing has macroscopic, dynamic and economic characteristics. The method can make up for the shortcomings of traditional drought monitoring methods. We can take targeted measures to alleviate the drought according to the drought characteristics identified by remote sensing. Presently, remote sensing has been a frequently-used drought monitoring method in agriculture because of it usability, timeliness and economy.

\footnotetext{
* Corresponding author: Tao Liu, Researcher, Saaslt@163.com
} 
Presently, there are many methods for monitoring drought using remote sensing data, including thermal inertia, vegetation index, temperature index, microwave remote sensing method, comprehensive vegetation and temperature index, etc. Each method has its own scope of application, advantages and disadvantages. At present, a method used and studied frequently is the integration of vegetation index and temperature, which is called the normalized difference vegetation index - surface temperature (NDVI-Ts) feature space method. Some studies have shown that soil moisture content is closely related to surface temperature and vegetation growth status. Usually, land surface temperature (Ts) had a close negative correlation with the normalized vegetation index (NDVI) [1]. Object show the triangular distribution in NDVI-temperature space where the NDVI and temperature derived from remote sensing data represented horizontal and vertical axes, respectively [2,3]. The scatter plots are trapezoidal, which constitute a specific NDVI-Ts feature space [4]. And there are a series of isopleth of soil moisture in the NDVI-Ts feature space [5]. Goward et al. [6] retrieved soil moisture using constructed NDVI-Ts feature space.

In China, the Temperature Vegetation Dryness Index (TVDI) based on vegetation index and land surface temperature is found to have a significant correlation with soil moisture, and TVDI can reflect changes of drought [7,8, 9,10]...Moreover, Ji et al improved the TVDI using Landsat8 data, and proposed an modified temperature vegetation index (MDTVDI) based on dry side revision to invert soil moisture. Compared with TVDI, MDTVDI has a higher accuracy for monitoring of regional drought [11].

In recent years, drought occurred frequently in Gaomi city of Shandong province and the surrounding area, which had a great impact on agricultural production. The local water conservancy and agriculture departments have to take several measures to alleviate the drought. Monitoring and forecast the drought are a very important work. In this study, a region in Gaomi city was selected as a study area. The purpose of the study was to study the drought monitoring method and construct the drought monitoring model in Gaomi city.

\section{$2 \quad$ Materials and methods}

\subsection{Study area}

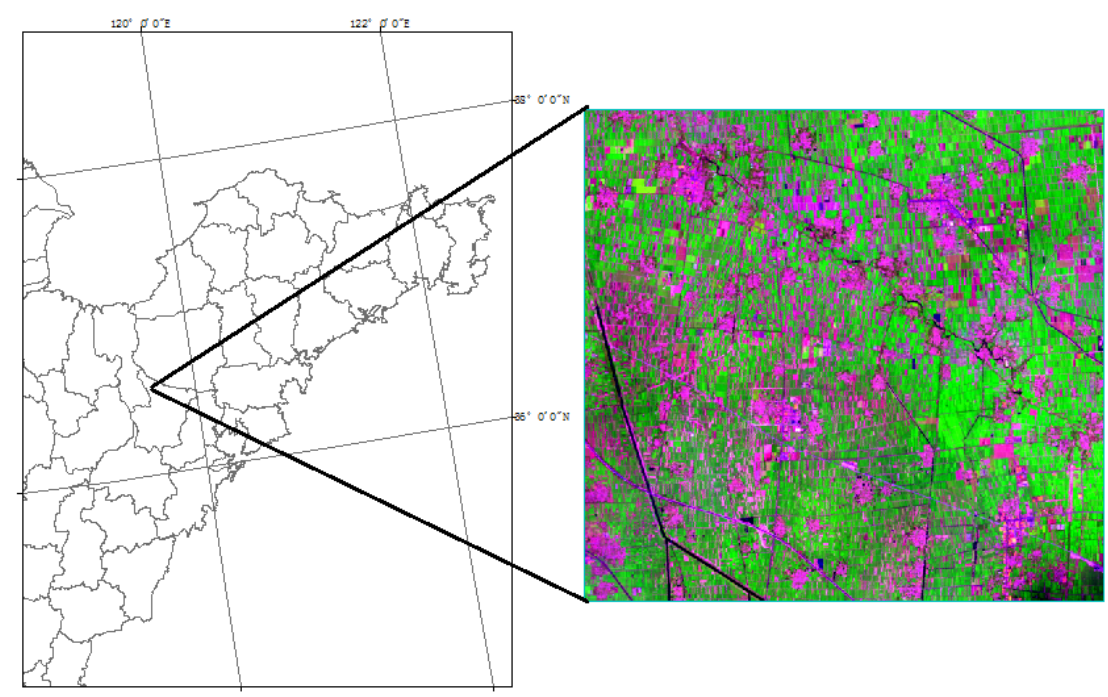

Fig.1. Location of study area

In consideration of the actual situation of drought in Gaomi city, the surrounding region of Da mujia town was selected as a study area (Fig.1). The study area is 
located in the junction of Gaomi, Pingdu and Changyi. The territory is dominated by plains and Gaomi has temperate continental semi-humid monsoon climate with cold winter and hot summer. In summer, there's more rain and hotter. However, there is dry and cold in winter and it has less rain and snow with prevailing northwest wind. Drought has occurred in Gaomi city and its surrounding areas for three consecutive years (2013-2016). Though field farmland survey, different degrees of drought have occurred in town of Da Mujia in April, 2017. Drought can seriously affect the yield of wheat, especially in the main growing season of wheat between March and June.

\subsection{Data}

According to the characteristics of drought and to meet the needs of remote sensing monitoring of small-scale regional scale, Landsat8 data is adopted in this study. Landsat8 satellite was launched in February 11, 2013 with two sensors. One is Operational Land Imager (OLI) and the other one is Thermal Infrared Sensor(TIRS) Compared with Landsat7, OLI adds a coastal / aerosol band and a cirrus band for detecting cirrus clouds in addition to all spectral bands of Landsat7. In addition, the spectral range of panchromatic and near-infrared bands is narrower. The radiation resolution of each band of Landsat8 increases from 8bit to 12bit, which increases the gray quantization level of the image, and improves the signal-to-noise ratio. TIRS has two thermal infrared bands, adding a thermal band with a resolution of $100 \mathrm{~m}$ compared with ETM+, making atmospheric correction easier.

In this study, Landsat8 remote sensing image on May 2, 2017 was downloaded. The location of the study area is free of cloud and fog. Moreover, MODIS11A1 data for the study area on May 2, 2017 was used. The data is the land surface temperature data with spatial resolution $1 \mathrm{~km}$, which was used as a parameter data when deriving surface temperature using Landsat8. The volumetric water content of the surface soil was measured with an instrument of Field Soil Moisture Measurement on May 2, 2017. In field experiments, land sampling spots with different vegetation coverage and different drought conditions were selected and measured. For each sample spot, five measurements were carried and their average value was adopted as final measurement result. The location of each sampling spot was recorder using GPS.

\subsection{Methods}

NDVI-Ts feature space and TVDI. NDVI and temperature data constitute a triangle NDVI-Ts feature space (Fig.2). Sandholt founded that a series of soil moisture contours exist in the NDVI-Ts feature space and these contours intersect at the intersection of dry and wet edges, and approximate to the straight line, and the slopes of these lines are linear relationship with soil moisture [5]. Based on this, the Temperature Vegetation Dryness Index (TVDI) was put forward.

$$
T V D I=\frac{T_{S}-T_{S \min }}{T_{S \max }-T_{S \min }}
$$

where $T_{\operatorname{Smin}}=\mathrm{a}+\mathrm{b} \times \mathrm{NDVI}$,

$$
\begin{aligned}
& T_{\text {Smax }}=\mathrm{c}+\mathrm{d} \times \mathrm{NDVI} \\
& \mathrm{NDVI}=\frac{R_{5}-R_{4}}{R_{4}+R_{5}}
\end{aligned}
$$

where $T_{S}$ is the surface temperature of any pixel in the image; $T_{S \min }$ is the minimum surface temperature corresponding to NDVI, namely the wet edge; $T_{S \max }$ is the maximum surface temperature corresponding to NDVI, namely the dry edge; a, b, c, and $d$ represent respectively linear fitting parameters for dry edges and wet edges; 
$R_{4}$ and $R_{5}$ are the reflectance of near-infrared and red band of OLI images, respectively.

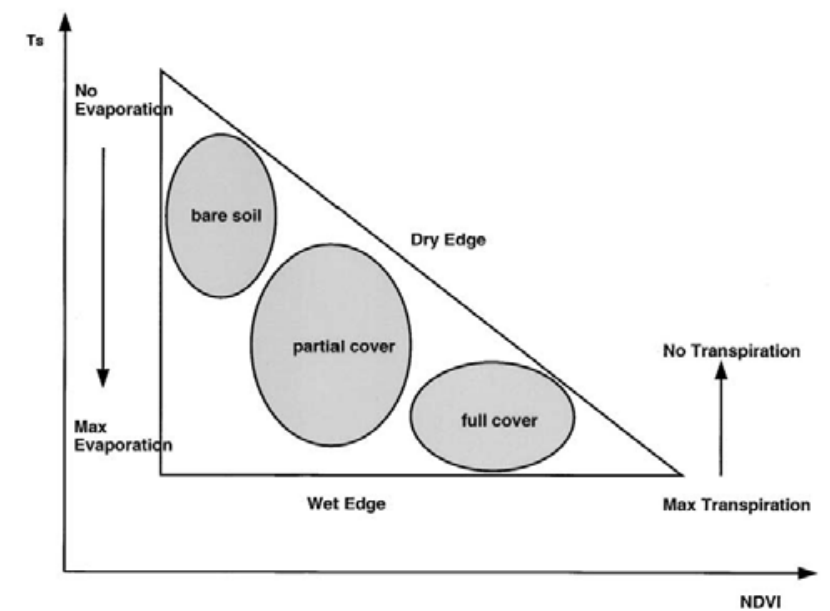

Fig. 2. Temperature and NDVI space

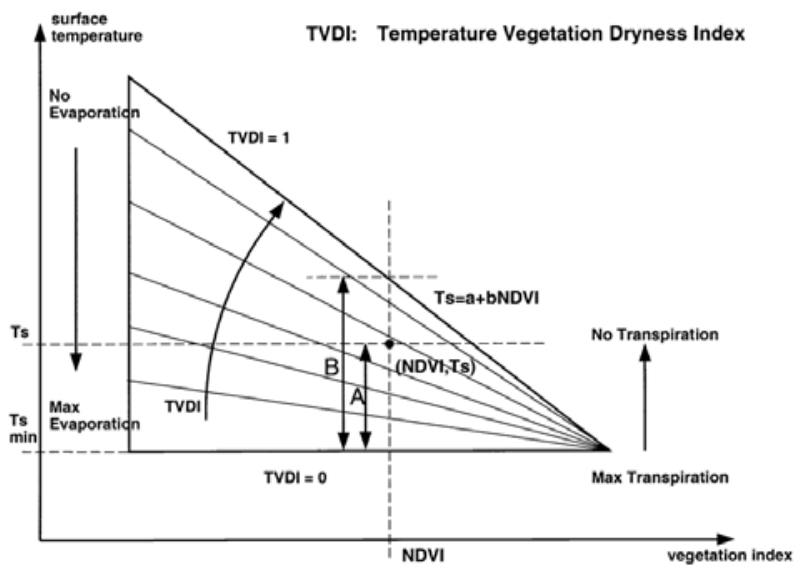

Fig. 3. Schematic diagram of Temperature Vegetation Dryness Index (TVDI)

TVDI is related to soil moisture and the values of TVDI are 1 and 0 for dry and wet edges, respectively (Fig. 3). The greater the value is, the lower the soil moisture is. The situation of the drought is worse. Inversely, the smaller the value is, the higher the soil moisture is.

Land surface temperature from Landsat 8.The single window algorithm was used to retrieve the temperature from the tenth band of TIRS images[12]. The formula is as follows:

$$
T_{S}=\frac{\left\{a(1-C-D)+[b(1-C-D)+C+D] T_{\text {sensor }}-D T_{a}\right\}}{C}
$$

where, a $=-67.355351$,

$\mathrm{b}=0.458606$,

$\mathrm{C}=\varepsilon^{\times} \times \tau, \mathrm{D}=(1-\bar{\eta}) \times[1+(1-\mathrm{g}) \times \tau$,

$\varepsilon$ is surface emissivity, $\tau$ is atmospheric transmittance, $T_{\text {sensor }}$ is brightness temperature of the sensor (unit: $\mathrm{K}$ ), $T_{a}$ is atmospheric mean temperature (unit: $\mathrm{K}$ ). The surface emissivity is one of important parameters to calculate the surface temperature. The ratio of surface emissivity is positively correlated to NDVI [13]. The emissivity of the earth surface can be calculated through NDVI.

$$
\varepsilon=1.0094+0.047 \times \ln (\mathrm{NDVI})
$$

The formula is applicable when NDVI varies between 0.157 and 0.727 . When the NDVI value is less than 0 , the main body is water. According to the study of [14], $\varepsilon$ 
for water can be approximated to 0.995 . Buildings in the city have NDVI values of less than 0.157 , and $\varepsilon$ can be set to 0.923 . When NDVI is greater than 0.727 , the surface is covered by vegetation completely, and $\varepsilon$ can be approximated to 0.986 .

Because the research area is relatively small, the atmospheric transmittance in the study area can be directly obtained from the relevant sites (http://atmcorr.gsfc.nasa. gov/). The atmospheric mean temperature is calculated using the mid-latitude summer empirical model.

$$
T_{a}=16.0110+0.92621 \times T_{0}
$$

where $T_{a}$ is atmospheric mean temperature. $T_{0}$ is the near surface mean air temperature (unit: $\mathrm{K}$ ), which is obtained from the MODIS temperature product data.

According to Planck's law, radiance received by sensor can be converted to brightness temperature. The formula is as follows.

$$
T_{\text {sensor }}=\frac{K_{2}}{\ln \left(\frac{K_{1}}{K_{\lambda}}+1\right)}
$$

where, $K_{\lambda}$ is apparent radiation ( $\mathrm{W} / \mathrm{m}^{2} \cdot \mathrm{sr} \cdot \mu \mathrm{m}$ )

$K_{1}$ and $K_{2}$ can be obtained directly from the field of K1_CONSTANT_BAND_10 and K2_CONSTANT_BAND_10 of thermal infrared band tenth band, which can be founded in the header file of Landsat8.

\section{$3 \quad$ Results}

\subsection{NDVI and land surface temperature}

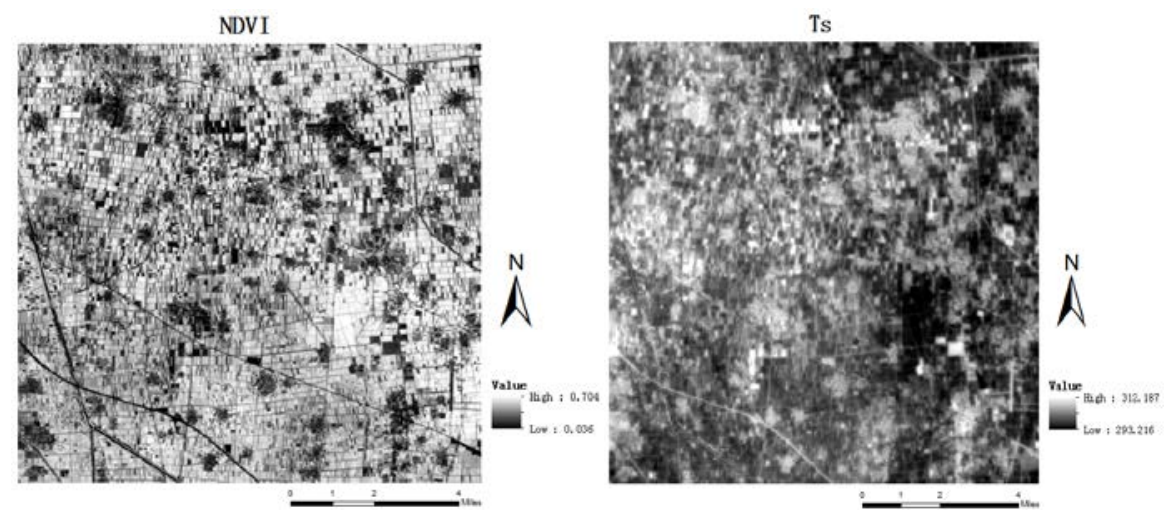

Fig. 4. Distribution map of NDVI and Temperature in the study area

The NDVI and the land surface temperature (Ts) in the study area were shown in Fig.4. Table 1 is a comparison between the land surface temperature from MODIS temperature product and the inversion of the land surface temperature from Landsat8. It can be seen that there is a good agreement between MODIS product and temperature from Landsat8. NDVI and Ts show an obviously negative correlation.

Table 1. Temperatures from MODIS and Landsat8

\begin{tabular}{ccccc}
\hline Ts & Min & Max & Average & Standard Deviation \\
\hline MODIS & 298.620 & 305.380 & 301.318 & 1.175 \\
Landsat8 & 293.216 & 312.674 & 300.674 & 2.854 \\
\hline
\end{tabular}

\subsection{TVDI and soil water}

The NDVI-Ts feature space was shown in Fig. 5. With the increase of NDVI value, the maximum value of land surface temperature firstly raised and then decreased. The minimum of land surface temperature showed a downward trend. The fitting 
equations of the dry edge and wet edge were as shown in Table 2.

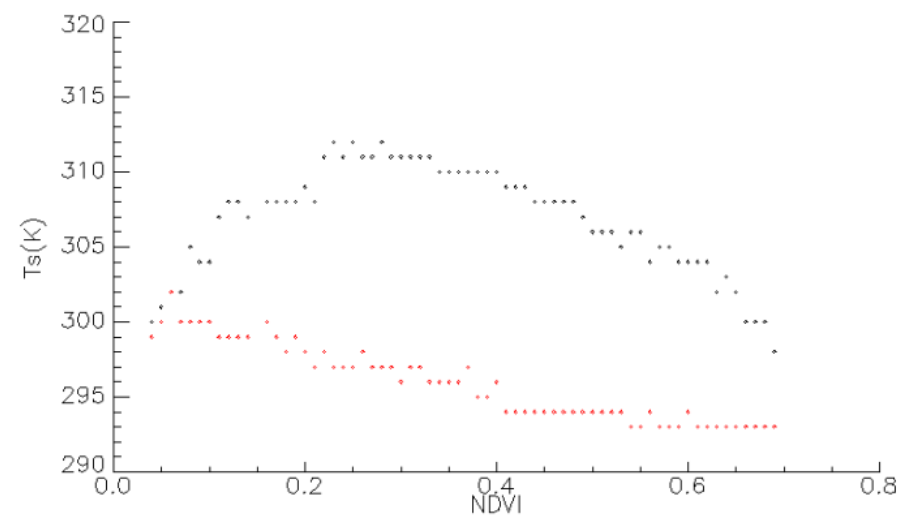

Fig. 5. NDVI-Ts feature space map

Table 2. The fitting equation of dry and wet edge

\begin{tabular}{ccc}
\hline & Equation & $\mathrm{R}^{2}$ \\
\hline Dry edge & $\mathrm{y}=-18.9061 \mathrm{x}+315.405$ & 0.714 \\
Wet edge & $\mathrm{y}=-11.8849 \mathrm{x}+300.199$ & 0.887 \\
\hline
\end{tabular}

Based on the fitting equation of the dry and wet edge, the TVDI of each pixel in the study area can be calculated. Based on the soil moisture content measured on the spot in the study area and the TVDI value of each spot, the correlation between them was analyzed and the result was shown in Fig 6. The correlation coefficient was 0.724 and passed the significance test of $0.01(\mathrm{p}<0.01)$. It indicated that there was high correlation between TVDI and soil water content. With the increase of TVDI value, the volumetric water content of soil decreases gradually.

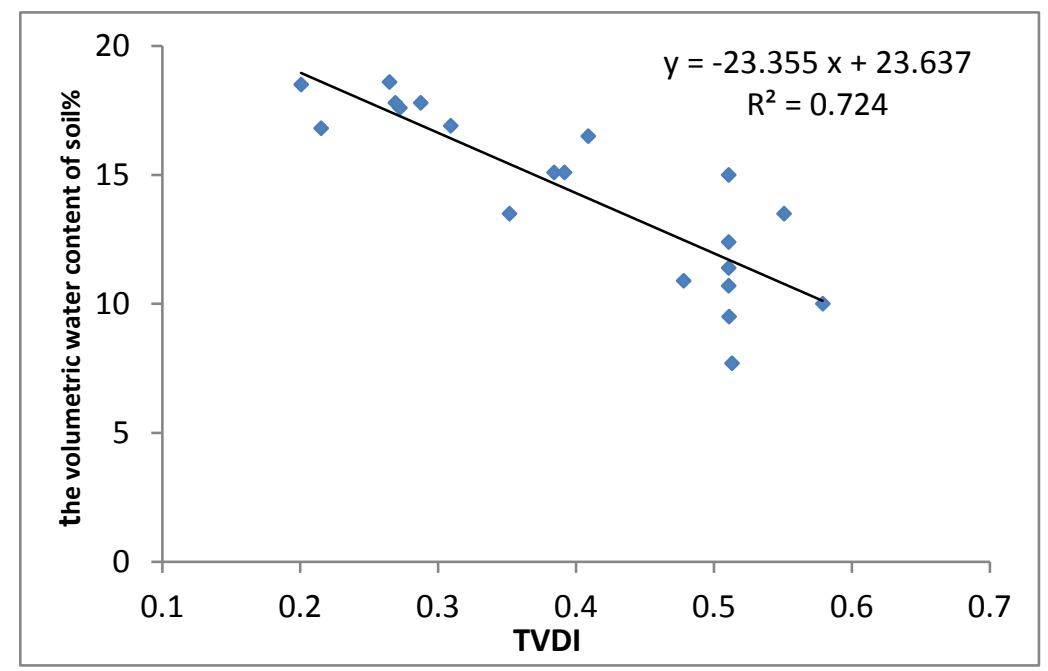

Fig. 6. Soil water content of and TVDI

\subsection{Drought distribution}

The good correlation between TVDI and the soil water content indicated TVDI was suitable for monitoring the drought in the study. According to the drought classification standard proposed by Qi Shuhua[7], the drought degree in the study area 
was divided into 5 grades: wet $(0<$ TVDI $<=0.2)$, normal $(0.2<$ TVDI $<=0.4)$, light drought $(0.4<$ TVDI $<=0.6)$, drought $(0.6<$ TVDI $<=0.8)$, heavy drought $(0.8<$ TVDI $<=$ $1)$. The drought distribution in the study area was shown in Fig. 7.

According to the drought distribution map, drought has occurred in the study area and the drought in the northeast was rather heavy. The areas of wet and normal accounted for $22.75 \%$ and the drought in the region accounted for $77.25 \%$.The light drought accounted for $46.71 \%$ of the entire region. Therefore, corresponding measures should be taken to alleviate the drought and prevent further aggravation of the drought.

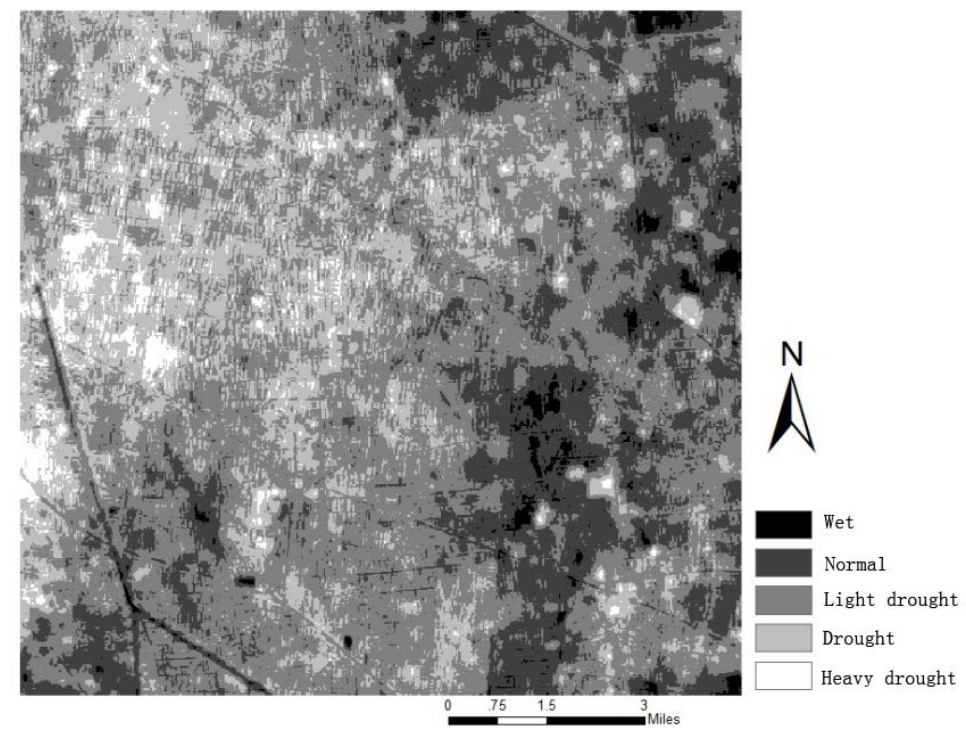

Fig. 7. The drought distribution map

\section{Conclusions}

Drought monitoring is a very import work in semi-humid and semi-arid regions because of its harmfulness. Its impact on crop production is especially serious. In this study, the surrounding areas of Gaomi city, Shandong province was selected to as a study area because there is frequently drought in recent years. On the basis of field investigation on soil water content, the drought monitoring method based on remote sensing was studied. In our study, the Landsat8 remote sensing data was used as the mainly data source. The land surface temperature and NDVI were derived from remote sensing data, and TVDI was calculated. Based on TVDI, the drought situation in the study was analyzed and an inversion model of soil water was constructed. The conclusions of the study are as follows.

(1) There is an obviously negative correlation between the land surface temperature and NDVI. The land surface temperature decreases with the increase of NDVI.

(2) TVDI can effectively reflect the drought in the study. The drought has already begun and the area of the drought occurred accounted for $77.25 \%$ in the study area.

(3) Soil water content is inversely related to TVDI. The soil water content decreased with the increase of TVDI.

TVDI is a good index in indicating agriculture drought. However, there are some limitations in TVDI. In the study, TVDI is suitable for monitoring drought. The area is small, so more studies is needed to test the applicability of TVDI in the larger area. 
Acknowledgments. This work was funded by Shandong Major Project for Application Technology Inovation of Agriculture(2016) and Key Technology Program of Key Industry in Shandong Province(2016CYJS03A01-1)

\section{References}

1. Nemani, R.R., Running, S.W.: Estimation of Regional Surface Resistance to Evapotranspiration from NDVI and Thermal-IR AVHRR Data. J. Appl. Meteoro. 28,276284 (1989).

2. Price, J. C.: Using Spatial Context in Satellite Data to Infer Regional Scale Evapotranspiration. IEEE T. Geosci. Remote. 28,940-948(1990)

3. Carlson, T.N., Capehart, W.J., Gillies, R.R.: A New Look at The Simplified Method for Remote Sensing of Daily Evapotranspiration. Remote Sens. Environ. 54,161-167(1995)

4. Moran, M. S., Jackson, R. D., Raymond, L. H., et al.: Mapping Surface energy Balance Components by Combining Landsat Thematic Mapper and Ground-based Meteorological Data. Remote Sens. Environ. 30,77-87(1989)

5. Sandholt, I., Rasmussen, K., Andersen, J.: A Simple Interpretation of The Surface temperature/vegetation Index Space for Assessment of Surface Moisture Status. Remote Sens. Environ.79,213-224, (2002)

6. Goward, S.N., Xue,Y., Czajkowski, K.P. :Evaluating Land Surface Moisture Conditions from The Remotely Sensed Temperature/vegetation Index Measurements: An Exploration with The Simplified Simple Biosphere Model. Remote Sens. Environ.79,225-242(2002).

7. Qi, S., Wang, C., Niu, Z.: Evaluating Soil Moisture Status in China Using the Temperature/Vegetation Dryness Index (TVDI). J. Remote Sens. 5, 420-427(2003).

8. Yao, C., Zhang, Z., Wang, X.: Evaluating Soil Moisture Status in XinJiang Using theTemperature Vegetation Dryness Index . Remote Sens. Technology Appl. 6,473478(2004)

9. Zhang, S., Qin, Q., Hou, M., et al.: Remote Sensing and Impact Estimation for Sichuan Hot-drought Based on Temperature Vegetation Dryness Index. Trans. Chinese Soc. Agricultural Engineering. 9,141-146(2007)

10. Gao, Z., Gao, W., Chang, N. :Integrating Temperature Vegetation Dryness Index (TVDI) and Regional Water Stress Index (RWSI) for Drought Assessment with the Aid of LANDSAT TM/ETM+ Images. Int. J. Appl. EARTH Obs.13,495-503 (2011)

11.Ji, G., Hu, D., Wang, X., et al.: Drought Monitoring Based on Landsat 8 Data and Temperature-vegetation Index [J]. J.Natural Disasters. 2, 43-52 (2016).

12. Qin, Z., Zhang, M., Arnon, K., et al.: Mono-window Algorithm for Retrieving Land Surface Temperature from Landsat TM6 Data. Acta Geographica Sinica. 2001(04):456-466

13. Van de Griend, A.A, Owe, M.: On the Relationship between Thermal Emissivity and The Normalized Difference Vegetation Index for Natural Surfaces. Int. J. Remote Sens., 14,1119-1131(1993)

14. Masuda, K., Takashima, T., Takayama, Y.: Emissivity of Pure and Sea Waters for the Model Sea Surface in the Infrared Window Regions. Remote Sens. Environ. 24,313329(1988). 